\title{
SUCCESSFUL ESOPHAGEAL TRACHEOBRONCHOPLASTY FOR COMBINED TRACHEAL AND BRONCHIAL TRAUMATIC RUPTURE
}

Henri Porte, MD, Mathieu Langlois, MD, Charles H. Maquette, MD, Jacques Dupont, MD, Jean M. Anselin, MD, and Alain Wurtz, MD, Lille, France

From the Clinique Chirurgicale, Hopital Albert Calmette CHRU Lille, 59037 Lille Cedex, France.

Received for publication Nov. 17, 1997; accepted for publication Dec. 8, 1997.

Address for reprints: H. Porte, MD, Clinique Chirurgicale, Hopital Albert Calmette CHRU Lille, 59037 Lille Cedex, France.

J Thorac Cardiovasc Surg 1998;115:1216-8

Copyright (C) 1998 by Mosby, Inc.

$0022-5223 / 98 \$ 5.00+0 \quad \mathbf{1 2 / 5 4 / 8 8 0 0 5}$
A mother fell down a flight of stairs while carrying her 5-year-old son in her arms. As she fell, she tightened her grip around the child's chest, leading to a blunt chest trauma with reflex closure of the glottis associated with trauma to the head. A medical emergency unit found the boy unconscious with subcutaneous emphysema of the neck and both hemithoraces. He was intubated without sedation with a No. 5 cuffed nasotracheal tube, and positive-pressure ventilation was initiated.

On admission to the hospital 1 hour later, the child was conscious and his respiratory status remained stable. A 


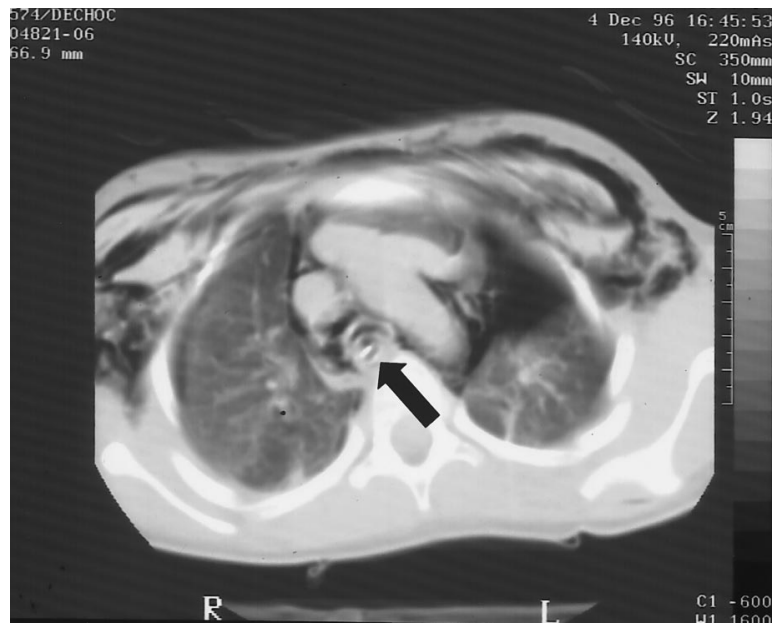

Fig. 1. Thoracic computed tomographic scan showing the esophagus protruding into the tracheal lumen (arrow).

chest radiograph showed a partial bilateral pneumothorax that was larger on the right side, with extensive subcutaneous and mediastinal emphysema. A thoracic computed tomographic scan showed that the esophagus was protruding into the tracheal lumen through its posterior wall (Fig. 1). Examination with a flexible bronchoscope revealed a $4 \mathrm{~cm}$ posterior longitudinal tear from the trachea to the right main bronchus. Despite bilateral pleural drainage, the child's respiratory status deteriorated rapidly and he was transferred to the operating room with acute respiratory failure. Selective ventilation of the left lung was not possible because the endotracheal tube could not be advanced far enough beyond the laceration into the left mainstem bronchus. A right lateral thoracotomy was quickly performed. As the posterior mediastinal pleura was progressively opened, detailed inspection of the injury revealed an $11 \mathrm{~cm}$ burstlike fracture with a major defect of the membranous pars from the trachea to the right main bronchus and the bronchus intermedius (Fig. 2, $A$ ). Gas exchange seriously deteriorated because of the extent of the air leak. An attempt to perform highfrequency jet ventilation with the tip of the gas inflow catheter advanced distal to the rupture failed. The acute condition of the patient and the length of the tracheobronchial rupture necessitated that an esophageal tracheobronchoplasty be performed to reconstruct the posterior wall of the trachea. The right edge of the esophagus was sutured to the right edge of the wound from the trachea to the bronchus intermedius with interrupted 5-0 absorbable monofilament sutures (Fig. $2, B)$. An immediate air seal was obtained. The tracheal tube was positioned above the superior edge of the wound before chest closure. Further recovery required bronchoscopic toilets each day to keep the airway clear of secretions.

The child was extubated on day 2 , the thoracic drains were removed on day 6 , and he was discharged on day 10 . A follow-up bronchoscopic examination at 3 months
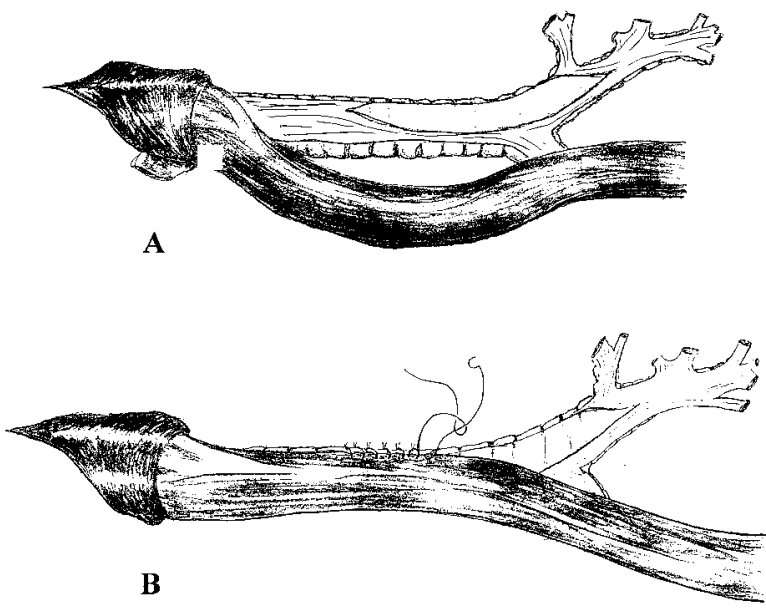

Fig. 2. A, Rupture of the membranous pars with a large defect from the trachea to the right main-stem bronchus and the bronchus intermedius. B, The right side of the rupture was sutured to the right side of the esophagus with interrupted monofilament absorbable suture.

showed that the tracheobronchial tree looked normal. The child was doing well without any symptoms 1 year after the operation.

Rupture of the tracheobronchial tree is an uncommon complication of blunt chest trauma. In our young patient, the reflex closure of the glottis together with thoracic compression produced a rapid increase in intraluminal pressure. This injury occurred when the child's mother tightened her grip around him, illustrating the fact that extreme violence is not essential for such burstlike lesions. $^{2}$ Overinflation of the tracheal cuff when the accident occurred may have contributed to the extent of the injury. Moreover, the extensive tearing of the membranous pars can be explained by further dissection with the aid of positive ventilatory support.

When a major tracheal or bronchial injury is suspected, bronchoscopy should be performed to establish the precise location of the injury. Nevertheless, this procedure can also lead to an underestimation of the extent of injury. ${ }^{3}$ Computed tomographic scans may also provide additional information regarding the severity of the injury, such as in the case described here where the esophagus was found to be protruding into the tracheal lumen.

Anesthetic management of the ruptured airway can be hazardous in pediatric patients. In the case of rupture of the carina or main bronchus, double-lumen tubes are not available in pediatric sizes, and tubes with bronchial blockers could exacerbate the injury. Consequently, selective intubation with the aid of bronchoscopic guidance with a long single-lumen tracheal tube is the best technique to achieve appropriate ventilation. ${ }^{4}$ Intubation of the left main bronchus through the operative field is another possibility. None of these maneuvers were possible in the case of the small child described here, however, whose condition was extremely unstable. An intraoperative air seal was the sole procedure available to us to 
restore proper ventilation. Tracheoplasty with the esophageal wall was initially described to treat patients with congenital tracheal stenosis. Niwa and associates ${ }^{5}$ first reported the delayed treatment of an iatrogenic tracheobronchial injury with this method.

The operative technique we used differed from the one described by Niwa, who sutured the left and right edges of the trachea to the esophagus.

This is, to our knowledge, the first report of such a technique being successfully used in an emergency to repair a tracheobronchial rupture. We used this procedure because it was the most expeditious way to achieve a perfect air seal. In addition, the abundant blood supply to the esophageal wall makes it superior to an isolated pericardial graft to repair such a large defect. The esophageal wall was completely epithelialized 3 months after the procedure was performed, and the absence of tracheobronchial stenosis by granulation tissue confirms that this technique can be used safely in young children.

In conclusion, esophageal tracheobronchoplasty is a simple and efficient method to obtain immediate and complete reconstruction of the tracheal wall in cases of extended burstlike trauma with further ad integrum recovery of both airway and esophageal functions.

\section{REFERENCES}

1. Thompson DA, Rowlands BJ, Walker WE, Kuykendall RC, Miller PW, Fischer RP. Urgent thoracotomy for pulmonary or tracheobronchial injury. J Trauma 988;28:276-80.

2. Martin de Nicolas JL, Gamez AP, Cruz F, Diaz-Hellin V, Marron C, Martinez JI, et al. Long tracheobronchial and esophageal rupture after blunt chest trauma: injury by airway bursting. Ann Thorac Surg 1996;62:269-72.

3. Baumgartner F, Sheppard B, De Virgilio C, Esrig B, Harrier $\mathrm{D}$, Nelson RJ, et al. Tracheal and main bronchial disruptions after blunt chest trauma: presentation and management. Ann Thoarc Surg 1990;50:569-74.

4. Newton JR, Sharma R, Azar H, Rummel MC, Britt LD. Successful reconstruction of a complex traumatic carinal disruption. Ann Thorac Surg 1996;62:284-6.

5. Niwa H, Masaoka A, Yamakawa Y, Hara F, Kondo K, Fukai I, et al. Esophageal tracheobronchoplasty for diseases of the central airway. J Thorac Cardiovasc Surg 1996;112:124-9. 